\title{
Range of motion implications of proximal humerus fractures: a case study
}

\author{
Anne J. H. Vochteloo • Peter R. Krekel • \\ Michiel A. J. van de Sande • Jochem Nagels
}

Received: 7 September 2011 / Accepted: 30 October 2011 /Published online: 16 November 2011

(C) The Author(s) 2011. This article is published with open access at Springerlink.com

\begin{abstract}
Background Functional outcome in surgical treatment of Neer three- and four-part proximal humerus fractures (PHF) varies greatly and depends on multiple parameters. Important parameters are the amount and direction of displacement and the necessary reduction of fragments during surgery. These are patient-specific parameters and are difficult to determine using traditional modalities such as radiographs and computed tomography $(\mathrm{CT})$.

Methods A 58-year-old female patient was reported in the emergency department with a three-part PHF. CT scan images showed that the humeral shaft was medialised and internally rotated, but with a marginally displaced greater tuberosity fragment. Using a bone-determined range of motion (ROM) simulation system, we analysed the CT scan and calculated the required correction needed to prevent post-operative impingement. The fracture was reduced and stabilised by a locking plate, realigning the medialised and internally rotated humeral shaft. The post-operative bonedetermined ROM was determined using a post-operative CT scan and the motion simulation system.

Results ROM limitations due to bony impingement visible in the simulations of the pre-operative CT scan had mostly disappeared in the simulations of the post-operative CT scan. Twelve weeks post-surgery the patient has regained close to $80 \%$ of her ROM.
\end{abstract}

\footnotetext{
A. J. H. Vochteloo $(\bowtie) \cdot$ P. R. Krekel • M. A. J. van de Sande J. Nagels

Department of Orthopaedics, Leiden University Medical Centre, PO box 9600, 2300 RC Leiden, The Netherlands

e-mail: ajhvochteloo@hotmail.com

P. R. Krekel

Computer Graphics Section, Delft University of Technology,

Delft, The Netherlands
}

Conclusions This case demonstrates the applicability of a new diagnostic tool that can be used to identify bony impingement and helps in making the decision for conservative or surgical treatment of a PHF. The simulation of post-trauma function was indicative of functional outcome. This supports our claim that the system may be used to facilitate the treatment decision regarding PHF.

Keywords Proximal humerus fracture - Medialisation . Range of motion · Imaging $\cdot$ Simulation $\cdot$ Operative treatment

\section{Introduction}

Proximal humerus fractures (PHFs) are more prevalent in elderly; the incidence rate is approximately 73/ 100,000 [1]. Depending on fracture severity, treatment can range from conservative to arthroplasty. Decision is based on age and patient expectations, on assessment of radiographs or computed tomography (CT) and on different fracture classification systems [2, 3]. However, the different classification systems have been much disputed for reproducibility and effectiveness in predicting outcome [4].

The severe implications of treatment decisions combined with the subjectivity of PHF classification systems encouraged us to investigate whether a computerised functional assessment of fractures adds support to optimal treatment decision. A critical aspect in the prediction of outcome of PHFs is altered bony morphology, leading to loss of range of motion (ROM) and persisting pain. In this report, we demonstrate the clinical use of a CT-based computerised functional simulation model in a relative young patient with a Neer three-part PHF. 

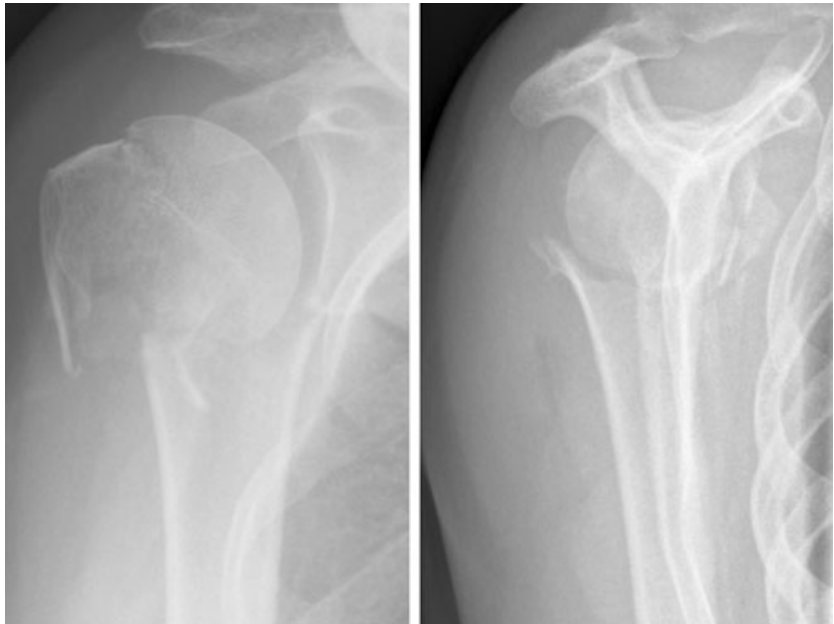

Fig. 1 Pre-operative AP and lateral radiographs. Only with the use of a CT scan the three-part proximal humerus fracture could be fully appreciated

\section{Case report}

The patient was a 58-year-old healthy woman who fell from her bike. Physical examination at the emergency department revealed a painful, slightly swollen right shoulder with ecchymosis, without neurovascular injury. X-rays (Fig. 1) showed a three-part PHF.

In this case, radiographs alone could potentially lead to misdiagnosing this fracture as a two-part with only slight medial displacement. CT imaging revealed a three-part

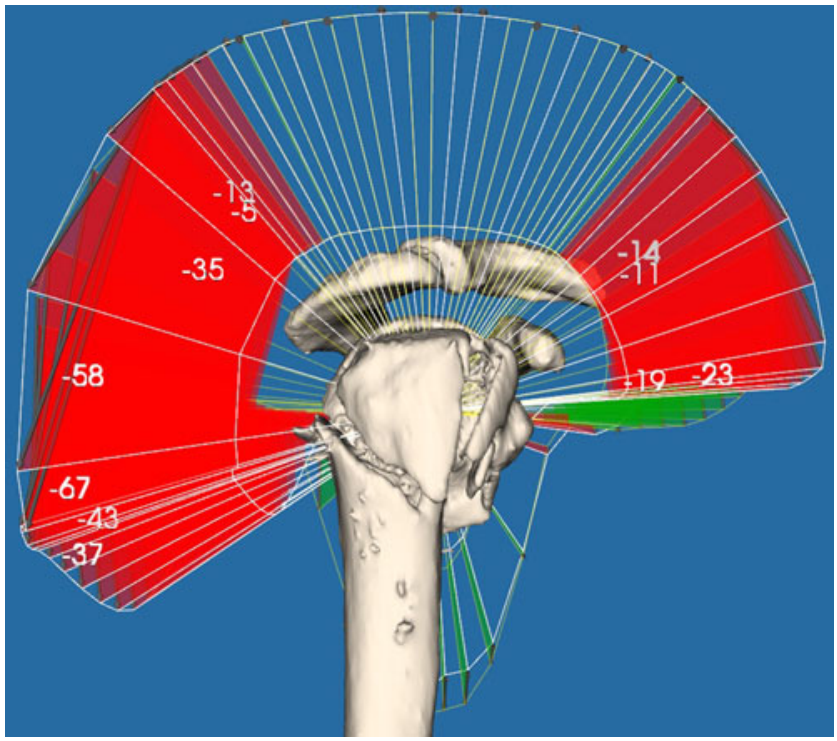

Fig. 2 Bone-determined ROM simulation compared to ROM simulations of a healthy subject. Using this simulation, we found a large ROM deficiency for external rotation and a relatively small deficiency for forward flexion. This is visualised by the red surfaces, the decrease of ROM is presented in degrees. No impingement of the tuberosities with the acromial arch is seen in this visualisation. Posterior limitations are caused by a limited external rotation range of only $4^{\circ}$
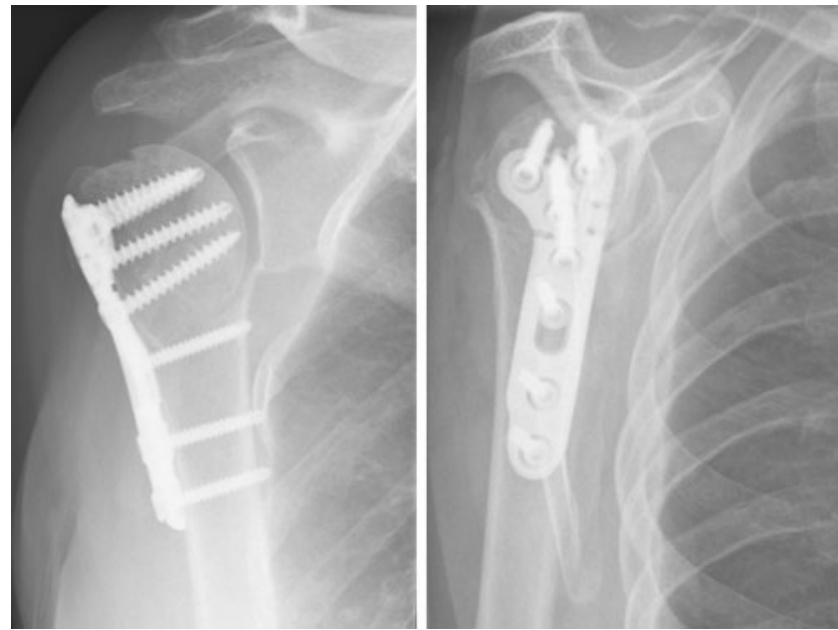

Fig. 3 Post-operative AP and lateral radiographs. Reduction of the greater tuberosity and correction of the medialisation and rotational displacement of the humeral shaft was achieved using an angular stable locking plate

fracture with significant medial displacement of the humeral shaft $(23 \mathrm{~mm})$ and internal rotation of $38^{\circ}$. Subsequently, the CT was analysed with Articulis software (Clinical Graphics, Den Haag, The Netherlands), designed for assessment and simulation of bone-determined ROM. It uses a kinematic model and collision detection to predict ROM, described in detail by Krekel et al. [5, 6]

Pre-operative simulation of ROM, assuming the fracture would have healed in this configuration, indicated that the available range of external rotation in $0^{\circ}$ adduction would be limited to $4^{\circ}$, due to medialisation and rotation of the

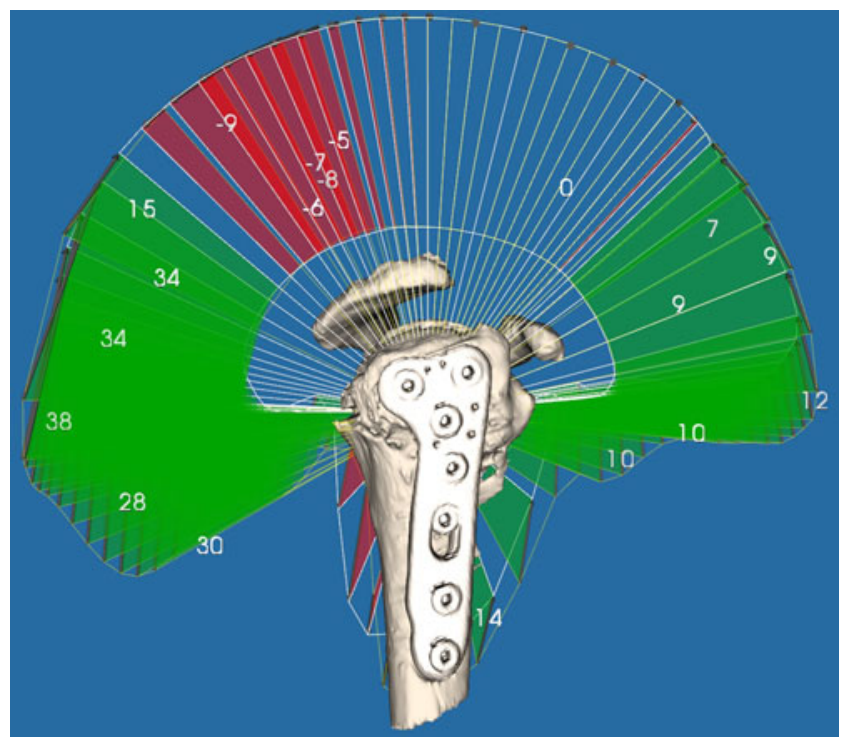

Fig. 4 Post-operative bone-determined ROM simulation compared to the pre-operative ROM simulations. A large part of the ROM limitations caused by the morphology of the fracture have been alleviated, as depicted by green surfaces. The change of bonedetermined ROM ranged from $-9^{\circ}$ to $38^{\circ}$ 
humeral shaft. According to the simulations, this limitation of external rotation would be nullified beyond $45^{\circ}$ of abduction, giving rise to the question whether this would be problematic in daily life. Although the greater tuberosity was clearly displaced, the ROM simulations did not show impingement between the greater tuberosity and the acromial arch (Fig. 2).

Conservative treatment was chosen because the predicted deficiency in ROM would not be limiting. However, in the first week of immobilisation, secondary radiologic displacement of fracture (further medialisation of the humeral shaft) occurred, probably due to displacing forces of amongst others teres minor and pectoralis major muscles. Therefore, it was decided to perform open reduction and internal fixation (ORIF), with an angular stable locking plate (Litos Tifix, Hamburg). Figure 3 shows post-operative radiographs.

Active forward flexion and circumduction were initiated directly post-operative. After 2 weeks, active physiotherapy was allowed with maximum forward flexion of $90^{\circ}$ and external rotation of $20^{\circ}$, followed by unrestricted training after 6 weeks. The patient gave an informed consent prior being included into this study.

\section{Radiological outcome and motion analysis}

Post-operatively, ROM simulations indicated that external rotation in adduction was now limited to $20^{\circ}$. Beyond $20^{\circ}$ of abduction, no limitation of external rotation and no impingement of the greater tuberosity occurred (Fig. 4). Plain followup X-rays showed normal fracture healing without secondary displacement or early signs of avascular necrosis.

\section{Clinical outcome}

ROM at 12 weeks post-operatively includes the following: active forward flexion $110^{\circ}$, external rotation in adduction $15^{\circ}$ and in $90^{\circ}$ of abduction $30^{\circ}$. Further improvement of the ROM is to be expected up to the first post-operative year $[7,8]$. The patient had no pain.

\section{Discussion}

There is an ongoing discussion whether or not to operate on PHF especially in the elderly patient, as sufficient proof from large prospective randomised clinical trials is lacking. A recent Cochrane analysis showed that three- and four-part fractures may not heal unless an adequate reduction and stabilisation are performed [9]. However, the very limited evidence available does not confirm that surgery is preferable to conservative treatment and complications associated with surgery need to be considered [10]. In this case, we first decided to treat the patient conservatively as the external rotation was mainly limited in adduction. However, due to secondary displacement, we decided to perform surgery. A second pre-operative CT scan for functional analysis was not performed, in order to minimise radiation exposure, since there was an indication for surgical treatment. We are confident that the analysis of the secondary displacement would have shown worse functional outcome.

The post-operative analysis showed a clear improvement of external rotation due to ORIF of the fracture. Despite the relatively short follow-up (12 weeks), functional recovery had already almost reached the predicted functional outcome levels. External rotation in adduction had reached $15^{\circ}$. This is a good clinical outcome when compared to the predicted $4^{\circ}$ for conservative treatment. It resembles the results of surgically treated PHFs found by Südkamp et al. [7]. The relatively small amount of posterior displacement of the greater tuberosity did not present a posterior impingement or a deficit in ROM in CT analysis. It is expected that further exercise can improve ROM in the next months.

As restoration of ROM, besides pain relief, should play a central role in choosing a treatment, this new technique may provide surgeons with a better tool to predict surgical success and patient satisfaction. The ability to choose patients that may benefit the most from surgery in an early stage of the treatment may not only improve functional outcome after surgically treatment, but also provide for a better informed consent.

Of course the key to success for this new CT-based simulation in predicting post-fracture ROM is its correlation to clinical outcome. Although just one case was evaluated, we believe that it is a promising technique to predict post-fracture ROM, assuming there is no additional pathology to the rotator cuff and abductor mechanism (deltoid muscle and axillary nerve). The hypothesis is that it is a helpful tool for choosing between conservative or operative treatment and should in the future be tested using a randomised controlled trial.

Conflict of interest The authors reported no conflict of interest.

Open Access This article is distributed under the terms of the Creative Commons Attribution Noncommercial License which permits any noncommercial use, distribution, and reproduction in any medium, provided the original author(s) and source are credited.

\section{References}

1. Van Staa TP, Dennison EM, Leufkens HG, Cooper C (2001) Epidemiology of fractures in England and Wales. Bone 29 (6):517-522 
2. Hertel R, Hempfing A, Stiehler M, Leunig M (2004) Predictors of humeral head ischemia after intracapsular fracture of the proximal humerus. J Should Elbow Surg 13(4):427-433

3. Neer CS (1970) Displaced proximal humeral fractures. I. Classification and evaluation. J Bone Joint Surg (Am) 52 (6): 1077-1089

4. Siebenrock KA, Gerber C (1993) The reproducibility of classification of fractures of the proximal end of the humerus. J Bone Joint Surg (Am) 75(12):1751-1755

5. Krekel PR, Botha CP, Valstar ER, de Bruin PW, Rozing PM, Post FH (2006) Interactive simulation and comparative visualisation of the bone-determined range of motion of the human shoulder. In: Schulze T, Horton G, Preim B, Schlechtweg S (eds) Proceedings of simulation and visualization. SCS Publishing House, Erlangen, pp 275-288

6. Krekel PR, de Bruin PW, Valstar ER, Post FH, Rozing PM, Botha CP (2009) Evaluation of bone impingement prediction in preoperative planning for shoulder arthroplasty. J Eng Med Part H: Proc IMechE 223(7):813-822

7. Südkamp N, Bayer J, Hepp P, Voigt C, Oestern H, Kääb M, Luo C, Plecko M, Wendt, Köstler W, Konrad G (2010) Open reduction and internal fixation of proximal humeral fractures with use of the locking proximal humerus plate. Results of a prospective, multicenter, observational study. J Bone Joint Surg (Am) 91(6):1320-1328

8. Ricchetti ET, Warrender WJ, Abboud JA (2010) Use of locking plates in the treatment of proximal humerus fractures. J Should Elbow Surg 19(2 Suppl):66-75

9. Handoll HH, Gibson JN, Madhok R (2003) Interventions for treating proximal humeral fractures in adults. Cochrane database of systematic reviews (Online) (4) CD000434

10. Young TB, Wallace WA (1985) Conservative treatment of fractures and fracture-dislocations of the upper end of the humerus. J Bone Joint Surg Br 67(3):373-377 